\title{
GAMBARAN TINGKAT PENGETAHUAN ORANG TUA SISWA/I KELAS IV SDN 030329 TENTANG MASA PERGANTIAN GIGI SUSU DENGAN GIGI PERMANEN TERHADAP GIGI BERJEJAL DI DESA TIGA BARU KECAMATAN PEGAGAN HILIR KABUPATEN DAIRI TAHUN 2017
}

\author{
Susy Adrianelly Simaremare \\ Jurusan Keperawatan Gigi Poltekkes Kemenkes Medan
}

\begin{abstract}
Abstrak
Memasuki usia sekolah, gigi tetap mulai tumbuh sehingga dalam rongga mulut anak terdapat gigi campuran, yaitu terdapatnya gigi susu dan gigi tetap.Periode gigi bercampur dalam masa pertumbuhannya dapat menimbulkan gigi berjejal, apabila gigi berjejal dibiarkan dapat menyebabkan gangguan fungsi pengunyahan, berbicara dan penampilan. Penelitian bersifat deskriptif dengan metode survey yang bertujuan untuk mengetahui gambaran Tingkat Pengetahuan Orang tua Siswa/i Kelas IV SDN 030329 Tentang Masa Pergantian Gigi Susu dengan Gigi Permanen Terhadap Gigi Berjejal di Desa Tiga Baru Kecamatan Pegagan Hilir Kabupaten Dairi Tahun 2017. Data diperoleh langsung terhadap 30 siswa/i, dan pengambilan sampel dilakukan dengan cara membagikan kuesioner kepada siswa/i untuk diberikan kepada orang tua. Hasil penelitian Tingkat Pengetahuan Orang Tua Tentang Masa Pergantian Gigi Susu dengan Gigi Permanen Terhadap Gigi Berjejal di Desa Tiga Baru Kecamatan Pegagan Hilir Kabupaten Dairi yang menjawab dengan kriteria sedang 20 orang (66,7\%),kriteria baik sebanyak 9 orang (30\%), dan kriteria buruk sebanyak 1 orang $(3,3 \%)$.Untuk frekuensi anak kelas IV SD yang tidak memiliki gigi berjejal sebanyak 20 orang $(66,7 \%)$ dan yang memiliki gigi berjejal sebanyak 10 orang $(33,3 \%)$. Diharapkan kepada orang tua agar menjaga dan merawat gigi anak sejak dini agar tidak berjejal. Dari Hasil Penelitian dapat diambil kesimpulan bahwa Pengetahuan orang tua tentang masa pergantian gigi susu dengan gigi permanen terhadap gigi berjejal dengan kriteria sedang adalah sebanyak 20 orang (66,7\%). dan Jumlah anak yang tidak memiliki gigi berjejal adalah sebanyak 20 orang (66,7\%).Diharapkan kepada siswa/i agar dapat menjaga kebersihan gigi dan mulutnya dengan baik.dan kepada pihak sekolah agar menjalankan program UKGS dalam rangka meningkatkan kesehatan gigi dan mulut yang optimal.
\end{abstract}

Kata kunci : Masa Pergantian Gigi,Gigi Berjejal

\section{Latar Belakang}

Kesehatan merupakan salah satu bagian terpenting dalam kehidupan manusia yakni jasmani dan rohani. Kesehatan dapat tercapai dengan meningkatkan gizi, dengan membiasakan sikap hidup bersih serta meningkatkan mutu pelayanan kesehatan pada seluruh masyarakat.

Masyarakat perlu meningkatkan pengetahuan, sikap dan perilaku untuk menjaga kebersihan gigi dan mulut dengan menyikat gigi secara baik dan benar. Pemerintah telah mengupayakan program kesehatan gigi melalui kegiatan promosi, pencegahan, dan pengobatan gigi di pelayanan kesehatan seperti di Puskesmas dan Rumah Sakit.

Menurut data Riset Kesehatan Dasar (Riskedas) tahun 2007,penduduk Indonesia 75\% mengalami riwayat karies gigi dengan tingkat keparahan gigi sebanyak lima gigi setiap orang. Dapat dibayangkan betapa besar pelayanan kesehatan gigi apabila masyarakat menyadari penyakitnya dan datang berobat ke pelayanan. Ternyata hanya $7 \%$ penduduk yang menyikat gigi dengan benar dan $7 \%$ masyarakat yang bersedia berobat gigi. Lebih terlihat lagi dari rendahnya kemauan masyarakat yang memanfaatkan jasa pelayanan kesehatan.

Memasuki usia sekolah, gigi tetap mulai tumbuh sehingga dalam rongga mulut anak terdapat gigi campuran, yaitu terdapatnya gigi susu dan gigi tetap.Periode gigi bercampur dalam masa pertumbuhannya dapat menimbulkan gigi berjejal, apabila gigi berjejal dibiarkan dapat menyebabkan gangguan fungsi pengunyahan, berbicara dan penampilan.

Gigi berjejal juga dapat menyulitkan oklusi (berkontaknya gigi atas dan gigi bawah) dengan tidak sempurna.Lengkung gigi atas tidak sesuai dengan lengkung gigi bawah, karena letak gigi yang tidak teratur. Bisa jadi salah satu atau beberapa gigi tidak mempunyai kontak dengan gigi lawannya, sehingga pengunyahan tidak optimal.

Ketidakteraturan posisi gigi juga dapat menyebabkan otot dan sendi rahang sakit atau mengalami kelainan karena secara maksimal digunakan 
untuk gerakan pengunyahan sehingga keseimbangan sistem pengunyahan menjadi terganggu.

Untuk mengetahui sejauh mana pengetahuan orang tua tentang masa pergantian gigi susu dengan gigi permanen, peneliti ingin melakukan penelitian mengenai gambaran tingkat pengetahuan orang tua siswa/i kelas IV SDN 030329 tentang masa pergantian gigi susu dengan gigi permanen terhadap gigi berjejal di Desa Tiga Baru Kecamatan Pegagan Hilir Kabupaten Dairi Tahun 2017

\section{Perumusan Masalah}

Berdasarkan latar belakang perumusan masalah adalah bagaimana gambaran pengetahuan orang tua siswa-siswi kelas IV SDN 030329 tentang masa pergantian gigi susu dengan gigi permanen terhadap gigi berjejal di Desa Tiga Baru Kecamatan Pegagan Hilir Kabupaten Dairi Tahun 2017.

\section{Tujuan Penelitian}

Penelitian dilakukan bertujuan untuk mengetahui gambaran tingkat pengetahuan orang tua siswa/i kelas IV SDN 030329 tentang masa pergantian gigi susu dengan gigi permanen terhadap gigi berjejal di Desa Tiga Baru Kecamatan Pegagan Hilir Kabupaten Dairi Tahun 2017.

\section{Tujuan Khusus}

1. Untuk mengetahui gambaran tingkat pengetahuan orang tua tentang masa pergantian gigi susu dengan gigi permanen.

2. Untuk mengetahui ada tidaknya gigi siswa/i yang berjejal.

\section{Manfaat Penelitian}

1. Hasil penelitian diharapkan dapat memberikan informasi tentang masa pergantian gigi susu dengan gigi permanen terhadap gigi berjejal kepada orang tua di Desa Tiga Baru Kecamatan Pegagan Hilir Kabupaten Dairi, Tahun 2017.

2. Hasil penelitian diharapkan menjadi data dan informasi bagi peneliti lain yang sejenis.

\section{Kerangka Konsep}

Kerangka konsep adalah suatu hubungan antara konsep-konsep atau variabel-variabel yang diamati (diukur) melalui penelitian yang dilakukan. Variabel dibedakan menjadi dua yaitu:

1. Variabel bebas (independen) yakni yang sifatnya mempengaruhi atau sebab terpengaruh.

2. Variabel terikat (dependen) yakni sifatnya tergantung akibat atau terpengaruh (Soekidjo, 2005).

\footnotetext{
Tingkat pengetahuan Orang tua tentang masa Pergantian gigi susu Dengan gigi permanen Gigi Berjejal permanen

Variabel Independen Variabel Dependen
}

\section{Defenisi Operasional}

1. Pengetahuan orang tua tentang masa pergantian gigi susu dengan gigi permanen adalah pemahaman orang tua mengenai masa pergantian gig susu dengan gigi permanen yang diperoleh dari hasil kuesioner yang diisi oleh orang tua.

2. Gigi berjejal atau crowed adalah gigi yang tumbuh dengan posisi / letak gigi yang tidak teratur susunannya pada rahang atas dan rahang bawah.

\section{Jenis dan Desain Penelitian}

Jenis penelitian yang dilakukan adalah penelitian deskriptif dengan metode survei. Penelitian bertujuan untuk mengetahui gambaran pengetahuan orang tua siswa/i kelas IV SDN 030329 tentang masa pergantian gigi susu dengan gigi permanen terhadap gigi berjejal pada orang tua di Desa Tiga Baru Kecamatan Pegagan Hilir Kabupaten Dairi.

\section{Lokasi penelitian}

Lokasi penelitian dilakukan di Desa Tiga Baru Kecamatan Pegagan Hilir Kabupaten Dairi.

\section{Populasi}

Populasi adalah keseluruhan objek penelitian atau objek yang diteliti (Notoadmojo, 2005). Populasi yang diambil dalam penelitian ini adalah 40 orang tua yang ada di Desa Tiga Baru Kecamatan Pegagan Hilir Kabupaten Dairi.

\section{Sampel}

Sampel adalah sebagian yang diambil dari keseluruhan objek yang diteliti dan dianggap mewakili seluruh populasi (Notoadmojo, 2005). Sampel dalam penelitian ini adalah jumlah sampel minimal yang berjumlah 30 orang.

\section{Jenis dan Cara Pengumpulan Data}

Jenis data yang diambil adalah data primer yang diperoleh langsung pada siswa.Data tentang tingkat pengetahuan diperoleh orang tua dari kuesioner sedangkan data tentang pemeriksaan gigi berjejal diperoleh dari pemeriksaan langsung pada siswa jumlah pertanyaan didalam kuesioner adalah 15 pertanyaan.Data diambil oleh peneliti ke lokasi penelitia.

Dalam penelitian ini peneliti melakukan pengambilan data sebagai berikut:

1. Peneliti membagikan kuesioner kepada siswa/i untuk diberikan kepada orang tua dan dikumpulkan keesokan harinya.

2. Peneliti memeriksa keadaan pertumbuhan gigi siswa/i (ada tidaknya gigi berjejal).

Dalam pemeriksaan gigi berjejal menggunakan alat sebagai berikut:

1. Alat-alat terdiri dari:

- Kaca mulut

- $\quad$ Pinset

- Nier bekken

- Kuesioner 
Untuk memperoleh tinggi kriteria tingkat pengetahuan orang tua digunakan rumus sebagai berikut:

$\begin{aligned} \text { Rumus } & =\frac{\text { Skor maksimum-Skor minimum }}{3} \\ & =\frac{15-0}{3} \\ & =\frac{15}{5}=3\end{aligned}$

Kriteria pengetahuan tinggi, sedang, rendah yang diperoleh adalah:

$\begin{array}{ll}\text { Baik } & : 11-15 \\ \text { Sedang } & : 6-10 \\ \text { Buruk } & : 0-5\end{array}$

\section{Pengolahan Data dan Analisa Data \\ Pengolahan Data}

Data yang telah dikumpul diolah secara manual dan dipindah ke dalam tabel distribusi frekuensi dengan langkah-langkah sebagai berikut:

\section{Proses Editing}

Proses editing dilakukan dengan memeriksa kuesioner yang telah diisi dengan tujuan data yang masuk dapat diolah secara benar sehingga pengolahan data memberikan hasil yang menggambarkan masalah yang diteliti, kemudian data dikelompokkan dengan menggunakan aspek pengukuran.

2. Proses Coding

Proses coding dilakukan dengan merubah jawaban responden kedalam bentuk angka-angka sehingga mempermudah dalam pengolahan data.

3. Proses Tabulating

Memasukkan data penelitian ke dalam tabel untuk mempermudah analisis data dan pengolahan data serta pengambilan kesimpulan.

\section{Analisa Data}

Data yang telah dikumpulkan diolah secara manual, diperiksa kelengkapan, kejelasan tulisan, ada tidaknya jawaban ganda dan pertanyaan-pertanyaan yang tidak dijawab. Data yang telah diisi oleh orang tua tersebut disederhanakan untuk mempermudah pengolahan dengan menggunakan angka atau kodekode tertentu pada penelitian yaitu:

1. skor 1 untuk jawaban benar.

2. skor 0 untuk jawaban salah.

Untuk mempermudah analisa dan pengolahan data serta pengambilan kesimpulan, data dihitung sesuai variabel yang telah ditentukan, kemudian dimasukkan ke dalam tabel distribusi frekuensi.

\section{Hasil Penelitian}

Penelitian tentang Gambaran Tingkat Pengetahuan Orang Tua Siswa/i Kelas IV SD 030329 Tentang Masa Pergantian Gigi Susu dengan Gigi permanen Terhadap
Gigi Berjejal yang di Desa Tiga Baru Kecamatan Pegagan Hilir Kabupaten Dairi Tahun 2017, diperoleh hasil sebagai berikut:

Tabel.1 Distribusi Frekuensi Berdasarkan Gambaran Tingkat Pengetahuan Orang Tua tentang masa pergantian gigi susu dengan gigi permanen terhadap gigi Berjejal di Desa Tiga BaruKecamatan Pegagan Hilir Kabupaten Dairi Tahun 2017

\begin{tabular}{|c|c|c|}
\hline $\begin{array}{c}\text { Kriteria } \\
\text { Pengetahuan }\end{array}$ & $\begin{array}{c}\text { (Sampel) } \\
\mathbf{n}\end{array}$ & $\begin{array}{c}\text { Persentase } \\
(\boldsymbol{\%})\end{array}$ \\
\hline Baik & 9 & 30 \\
\hline Sedang & 20 & 66,7 \\
\hline Buruk & 1 & 3,3 \\
\hline Jumlah & 30 & 100 \\
\hline
\end{tabular}

Berdasarkan tabel 1 dapat dilihat bahwa persentase tingkat pengetahuan orang tua tentang masa pergantian gigi susu dengan gigi permanen terhadap gigi berjejal dengan kriteria sedang sebanyak 20 orang $(66,7 \%)$, kriteria baik 9 orang (30\%), dan kriteria buruk 1 orang $(3,3 \%)$.

Tabel 2. Distribusi Frekuensi Ada Tidaknya Gigi Berjejal Pada Anak Kelas IV SDN 030329 di Desa Tiga Baru Kecamatan Pegagan Hilir Kabupaten Dairi Tahun 2017.

\begin{tabular}{|c|c|c|c|}
\hline No & Keadaan Gigi & $\begin{array}{c}\text { (Sampel) } \\
\mathbf{n}\end{array}$ & $\begin{array}{c}\text { Persentase } \\
(\%)\end{array}$ \\
\hline 1 & $\begin{array}{l}\text { Memiliki gigi } \\
\text { berjejal }\end{array}$ & 10 & 33,3 \\
\hline 2 & $\begin{array}{l}\text { Tidak Memiliki } \\
\text { gigi berjejal }\end{array}$ & 20 & 66,7 \\
\hline & Jumlah & 30 & 100 \\
\hline
\end{tabular}

Dari tabel 2 dapat dilihat bahwa jumlah Siswa/i yang tidak memiliki gigi berjejal adalah sebanyak 20 anak $(66,7 \%)$, sedangkan yang memiliki gigi berjejal sebanyak $10 \operatorname{anak}(33,3 \%)$.

\section{Pembahasan}

Berdasarkan tabel 1 dapat dilihat bahwa persentase tingkat pengetahuan orang tua tentang masa pergantian gigi susu dengan gigi permanen terhadap gigi berjejal dengan kriteria sedang sebanyak 20 orang $(66,7 \%)$, kriteria baik 9 orang (30\%), dan kriteria buruk 1 orang $(3,3 \%)$.

Dari kuesioner yang diberikan pada orang tua, (90\%) menjawab Kesehatan gigi susu sangat menentukan pertumbuhan dan perkembangan anak. Menurut Silviatri (2011) Kesehatan gigi susu sangat menentukan pertumbuhan dan perkembangan gigi tetap oleh.Silviatri menyarankan untuk menjaga kebersihan gigi susu, dan melakukan Pendekatan psikologis kepada anak. Peran aktif orang tua sangat dibutuhkan dalam perawatan gigi anak. biasanya, anak-anak tidak peduli dengan kondisi giginya. Hal ini menjadi tugas orang tua untuk mengajarkan anak tentang perlunya menjaga kebersihan dan kesehatan gigi. 
Dari kuesioner yang didapat tentang gigi susu rusak dapat menyebabkan gigi permanen tidak tumbuh teratur orang tua yang menjawab dengan benar sebanyak 5 orang $(16,7 \%)$.

Menurut Silvitri (2011) Untuk mencegah posisi gigi tidak teratur dapat dilakukan dengan beberapa cara. Tindakan-tindakan yang biasanya dilakukan petugas kesehatan gigi adalah dengan Menambal atau merawat gigi susu yang berlubang. Tindakan ini bertujuan untuk mencegah gigi susu yang tanggal sebelum waktunya,Mencabut gigi susu yang belum tanggal karena gigi tetap penggantinya sudah tumbuh dan Membuat alat sederhana untuk mempertahankan posisi ruangan pada lengkung gigi, apabila gigi susu tanggal sebelum waktunya.

Kebanyakan orang tua yang beranggapan bahwa gigi anak tidak berjumkah 20 itu dapat dilihat dari kuesioner yang talah dibagikan bahwa yang menjawab jumlah gigi anak 20 sebanyak 17 orang $(56,7 \%)$.

Menurut Nuzul Fauzan (2011) Umumnya ketika anak berusia 1 tahun mempunyai 6-8 gigi susu (tapi kadang ada juga yang hanya 2 gigi walaupun tanpa disertai keluhan pertumbuhan) dan akan menjadi lengkap berjumlah 20 gigi susu (4 gigi seri atas-bawah, 2 gigi taring kanan-kiri di atas-bawah, dan 4 geraham kiri-kanan di atas-bawah) pada usia 18 bulan atau 2 tahun. Kendati erupsi gigi pertama terjadi pada usia 6-8 bulan, namun masih belum bisa dikatakan terlambat apabila di atas usia tersebut belum juga keluar gigi pertama. Karena, normalnya erupsi gigi terjadi pada usia 6-12 bulan.

Dari pertanyaan kuesioner yang didapat tentang gigi yang dicabut sebelum waktunya dapat menyebabkan gigi berjejal yang menjawab benar sebanyak 22 orang $(73,3 \%)$.

Menurut Maulani (2006) Sebab lain adalah karena dilakukan pencabutan gigi susu terlalu dini, jauh sebelum gigi tetap pengganti dibawahnya muncul. Gigi susu merupakan penunjuk jalan gigi tetap sehingga gigi susu yang dicabut terlalu dini membuat gigi tetap dibawahnya kehilangan arah dan tumbuh bukan pada tempat semestinya. Dan dalam keadaan normal, secara berurutan gigi seri susu akan diganti dengan gigi seri tetap, gigi geraham (molar) susu akan diganti oleh gigi geraham kecil (premolar) tetap, dan gigi taring susu akan diganti oleh gigi taring tetap. Yang merupakan perkecualian adalah gigi geraham besar tetap. Gigi ini tidak menggantikan gigi susu, dan gigi geraham besar tetap pertama, mucul dalam rongga mulut (erupsi) pada usia 6 tahun.

pertanyaan kuesioner tentang pengetahuan Ibu bahwa gigi geraham tetap yang pertama kali tumbuh pada umur 6 tahun dan tidak akan berganti lagi yang menjawab pertanyaan ini sebanyak 13 orang $(43,3 \%)$.

Menurut Silviatri (2011) Gigi tetap pertama yang tumbuh pada usia 6-7 tahun, yaitu gigi geraham besar pertama (gigi 6) rahang atas dan bawah. Gigi ini sering dianggap sebagai gigi susu sehingga keberadaannya sering diabaikan. Para orang tua beranggapan bahawa apabila gigi ini berlubang, kedudukannya pasti digantikan oleh gigi tetap. Akibatnya, pada kebanyakan penderita gigi 6 ini paling sering berlubang dan akhirnya terpaksa dicabut.
Gigi anak yang pertama kali tumbuh adalah gigi seri pertama yang menjawap pertanyaan ini dengan benar sebanyak 21 orang $(70 \%)$.

Menurut Nunul Fauzan (2011) Pada dasarnya erupsi atau keluarnya gigi susu pertama terjadi di usia 6-8 bulan. Umumnya diawali oleh keluarnya gigi seri tengah bawah, lalu secara berurutan gigi seri tengah atas, gigi seri lateral atas dan gigi seri lateral bawah, geraham susu pertama, gigi taring dan geraham susu kedua. Erupsi gigi tidak sekaligus, melainkan satu per satu dan kadang ada juga yang sepasang-sepasang.

Posisi gigi berjejal dapat mempermudah makanan menempel pada gigi yang mejawab pertanyaan ini dengan benar sebanyak 26 orang $(86,7 \%)$.

Menurut Maulani (2006) Sesungguhnya merawat gigi bertumpuk lebih sulit daripada merawat gigi yang terletak dalam satu lengkung yang sama. Bila gigi berjejal yang terkena sikat gigi pada saat pembersihan adalah gigi pada lengkung terluar. Gigi yang berjejal sulit dibersihkan. Setelah selesai makan pun makanan lebih mudah tertinggal dan terselip pada gigi yang berjejal.

Dari kuesioner yang diberikan pengetahuan orang tua tentang posisi gigi yang tidak teratur dapat mengakibatkan pengunyahan yang tidak sempurna yang menjawab pertanyaan dengan benar sebanyak 25 orang $(83,3 \%)$.

Menurut Maulani (2006) Gigi berjejal juga menyulitkan oklusi (berkontaknya gigi atas dan gigi bawah) dengan sempurna. Sebab lengkung gigi atas dan bawah tidak selamanya bertemu, karena letaknya yang tidak teratur. Bisa jadi salah satu atau beberapa gigi tidak mempunyai kontak dengan gigi lawannya, sehingga pengunyahan pun tidak dapat berlangsung optimal. Tidak jarang ketidakteraturan gigi menyebabkan otot dan sendi rahang sakit/mengalami kelainan karena harus bekerja keras menciptakan keseimbangan sistem pengunyahan yang ditentukan juga oleh faktor lidah, otot dan sendi rahang selain dari gigi-gigi.

Gigi yang dicabut sebelum waktunya menyebabkan pergeseran gigi disebelahnya dapat menyebabkan penyempitan lengkung gigi akibatnya gigi permanen tidak memperoleh ruang yang cukup dan gigi akan tumbuh berjejal yang menjawab pertanyaan denga benar sebanyak 25 orang $(83,3 \%)$

Menurut Maulani (2006) Gigi yang dicabut sebelum waktunya atau Gigi yang berlubang pada bagian yang berkontak dengan gigi tetangganya, akan menyebabkan titik kontak gigi hilang dan dapat menyebabkan pergeseran gigi. Pergeseran gigi tetap kecenderungannya adalah ke arah mesial. (mesial adalah istilah sisi gigi yang mengarah ke garis tengah, sedangkan distal adalah permukaan yang menjauhi garis tengah, secara umum mesial dan distal adalah bagian proximal/approximal yang artinya terletak saling berdekatan). Pergeseran ini menyebabkan panjang lengkung rahang menjadi berkurang, sehingga gigi yang tumbuh belakangan, kekurangan tempat dan gigi akan berjejal.

Pengetahuan orang tua yang didapat dari kuesioner yang diberikan tentang gigi susu yang terlalu cepat dicabut dapat menyebabkan gigi tetap dapat tumbuh ditempat yang 
salah atau ditempat yang bukan seharusnya yang menjawab dengan benar sebanyak 16 orang $(53,3 \%)$.

Menurut Nuzul Fauzan (2011) Gigi tetap pertama biasanya muncul di usia 6 tahunan. Oleh karenanya,paling baik kalau gigi susu tanggal ketika gigi tetap penggantinya sudah teraba atau terlihat. Gigi susu harus dipertahankan karena merupakan penuntun erupsi bagi gigi tetap. Jika gigi susu copot sebelum waktunya gigi tetap keluar, maka gigi geligi "tetangganya" akan bergeser mengisi sebagian kavling yang kosong. Akibatnya, gigi tetap tumbuh tidak pada tempatnya atau berjejal.

Dari kuesioner pengetahuan Ibu yang didapat tentang gigi anak yang berjejal dapat dirapikan dengan menggunakan kawat gigi yang menjawab pertanyaan ini dengan benar sebanyak 17 orang $(56,7 \%)$.

Menurut Maulani (2006) Penanganan gigi untuk kasus dental adalah dengan alat orthodonti (alat untuk meratakan gigi). Alat orthodonti ada dua macam, yakni alat orthodonti lepasan dan alat orthodonti cekat. Alat lepasan dipakai terbatas untuk kasus yang mudah sedangkan alat orthodonti cekat dapat dipakai untuk kasus mudah dan sulit. Dokter gigi bukan spesialis, dapat mengerjakan perawatan dengan alat orthodonti lepasan. Pemakaian alat orthodonti umumnya dipakai pada saat gigi tetap sudah tumbuh semua (sekitar usia 15 tahun) dan batas maksimal usia tidak terbatas selama keadaan gigi serta tulang penyangganya dalam keadaan sehat. Lamanya perawatan gigi berjejal tergantung dari beratnya kasus. Untuk kasus yang sedang umumnya berkisar antara 1-2 tahun, dengan kontrol rutin ke dokter gigi setidaknya sebulan sekali untuk mengencangkan kawat.

Dari tabel 2 dapat dilihat bahwa jumlah Siswa/i yang tidak memiliki gigi berjejal adalah sebanyak 20 anak $(66,7 \%)$, sedangkan yang memiliki gigi berjejal sebanyak 10 anak $(33,3 \%)$.

Menurut Maulani (2006) Crowding merupakan suatu istilah yang umum dalam bidang kedokteran gigi untuk menggambarkan keadaan gigi yang berjejal/bertumpuk. Gigi yang berjejal bisa terjdi di beberapa tempat, pada gigigigi depan, gigi belakang atau pada tempat tertentu saja seperti gigi taring yang tidak kebagian tempat (sering disebut sebagai gingsul). Gigi gingsul/gigi taring yang berada lebih ke depan daripada lengkungnya di sebut sebagai caninus ectopic. (caninus = gigi taring, ectopic $=$ terdapat dalam posisi atau bentuk yang tidak biasa, jadi caninus ectopic $=$ gigi taring yang terletak pada posisi yang tidak biasanya).

\section{Kesimpulan}

hasil penelitain tentang Gambaran Tingkat Pengetahuan Orang Tua Siswa/i Kelas IV SD Tentang Masa Pergantian Gigi Susu dengan Gigi Permanen Terhadap Gigi Berjejal di Desa Tiga Baru Kecamatan Pegagan Hilir Kabupaten Dairi Tahun 2017 dapat diambil kesimpulan sebagai berikut::

1. Pengetahuan orang tua tentang masa pergantian gigi susu dengan gigi permanen terhadap gigi berjejal dengan kriteria sedang adalah sebanyak 20 orang $(66,7 \%)$.
2. Jumlah anak yang tidak memiliki gigi berjejal adalah sebanyak 20 orang $(66,7 \%)$.

\section{Saran}

Berdasarkan hasil penelitian yang telah dilakukan peneliti memberikan saran sebagai berikut:

1. Di harapkan kepada Siswa/i agar dapat menjaga kebersihan gigi dan mulut.

2. Diharapkan Kepada Pihak Sekolah SDN 030329 di Desa Tiga Baru Kecamatan Pegagan Hilir Kabupaten Dairi Tahun 2017 agar dapat bekerjasama dengan pihak Puskesmas untuk menjalankan program UKGS dalam rangka meningkatkan kesehatan gigi dan mulut yang optimal.

\section{DAFTAR PUSTAKA}

Afrilina, G, 2006, Masalah Gigi Anak dan Solusinya, PT Elex Media Komputindo,Jakarta.

Fauzan, Nurul, 2011, perkembangan gigi anak, http://kimsosil2toothsmile.wordpress.com/Diaksestang $\mathrm{gal} / 2-7-2017$

Indriyanti, R, dkk. 2011.Pergantian Gigi Susu Dengan Gigi Tetap Sumedang, http://pdgicabwngr. blogspot. com/2011/10/pergantian gigi-susu-dengangigi-tetap. html/Diakses tanggal 06/05/2017

Machfoedz,I, 2008,Menjaga Kesehatan Gigi dan Mulut Anak-Anak dan Ibu Hamil, Penerbit Fitrama, Yogyakarta.

Meliono, I, dkk, 2007, MPKT Modul 1, Lembaga Penerbitan FEUI, http://id.wikipedia.org/wiki/Pengetahuan/ Diakses tanggal 21/13/2017 Jakarta

Maulani, C dan Jubilee Enterprise, 2005,Kiat Merawat Gigi Anak, PT Elex Media Komputindo, Jakarta.

Maulani, C. 2006. Crowding.Jakarta. http://dention brave host.com/CROWDING.htm.Diakses Tanggal 03-052017

Notoatmodjo, S, 2005, Metodologi Penelitian Kesehatan, PT RINEKA CIPTA, Jakarta.

Notoatmodjo, S, 2003, Pendidikan dan Perilaku Kesehatan, Edisi Previsi, RINEKA CIPTA, Jakarta.

Nuraskin, C, A, dkk, 2012, Bahan Ajar Penelitian, USU Press, Medan.

Rahmadhan, A, G, 2010, Serba Serbi Kesehatan Gigi dan Mulut, Bukune, Jakarta.

Silvatri, 2011, Mencegah gigi tidak teratur sejak dini, http://kimsosil2toothsmile.wordpress.com/menceg ah-gigi-tidak-teratur sejak-dini/Diakses tanggal 306-2017. 